\title{
Pelayanan Prima Perawat Berdasarkan Persepsi Pasien di Ruang Rawat Inap Talaga Bodas (Penyakit Dalam Pria Kelas 3) Rumah Sakit Tingkat II 03.05.01 Dustira Cimahi 2019
}

\author{
Lilis Rohayani ${ }^{1}$, lin Inayah², Anisa Shofiyani Shoumi ${ }^{3}$, Andria Pragholapati ${ }^{4}$ \\ 1,2,3 STIKes Jenderal Achmad Yani, Cimahi \\ ${ }^{4}$ Universitas Pendidikan Indonesia \\ ${ }^{1}$ lilisrohayanililis@yahoo.com*; ${ }^{2}$ inayah_2006@yahoo.co.id; ${ }^{3}$ ASShoumi@yahoo.com \\ ${ }^{4}$ andria.pragholapati@upi.edu \\ *Corresponding author
}

\begin{tabular}{ll}
\hline Informasi artikel & ABSTRAK \\
\hline Received: 12-04-2020 & Pelayanan prima merupakan sikap atau cara pemberi layanan yang berperan \\
Revised: 27-05-2020 & besar dalam menciptakan kepuasan bagi pasien, maka upaya rumah sakit \\
Accepted: 31-05-2020 & untuk meningkatkan kualitas pelayanan serta kepuasan pasien adalah \\
& dengan menerapkan pelayanan pirma (service exellence). Faktor - faktor \\
& yang harus di terapkan oleh perawat dalam memberikan pelayanan prima, \\
\hline Kata kunci: & meliputi kemampuan (ability), sikap (attitude), penampilan (appearance), \\
Pelayanan Prima & perhatian (attention), tindakan (action) dan tanggung jawab (accountability). \\
Perawat & Penelitian ini bertujuan untuk mengetahui gambaran pelayanan prima \\
Rumah sakit & perawat berdasarkan persepsi pasien di ruang rawat inap Talaga Bodas \\
& (Penyakit Dalam Pria Kelas 3) Rumah Sakit Tk II 03.05.01 Dustira Kota \\
& Cimahi tahun 2019. Rancangan penelitian yaitu survey analytic. Jumlah \\
& sampel sebanyak 149 responden menggunakan teknik purposive Sampling \\
& dengan kriteria inklusi dan eksklusi. Pengumpulan data dilakukan \\
& menggunakan metode kuesioner skala Likert dengan 30 pertanyaan yang \\
& dibuat oleh peneliti dan dilakukan uji validitas dan reabilitas. Analisis data \\
& yaitu univariat untuk melihat distribusi frekuensi. Hasil penelitian \\
& menunjukkan sebanyak 80 responden (53,7\%) merasakan pelayanan prima. \\
& Disarankan menerapkan pelayanan prima (Ability, Attitude, Appearance, \\
& Attention, dan Action) kepada perawat yang dapat meningkatkan kualitas \\
pelayanan serta kepuasan pasien.
\end{tabular}

Key word:

Service Excellent

Nurse

Hospital

\begin{abstract}
Excellent service is an attitude or a way that provides great service in creating satisfaction for patients, hence supporting hospitals to improve service quality and patient satisfaction by using prima services (service excellence). Factors that must be applied by nurses in providing excellent service, providing ability (ability), attitude (attitude), appearance (appearance), attention (attention), action (action), and responsibility (accountability). This study aims to determine the description of excellent service nurses based on patient perceptions in the Talaga Bodas inpatient (Class 3 Male Disease) Kindergarten II Hospital 03.05.01 Dustira Cimahi City in 2019. The study design is an analytic survey. The total sample of 149 respondents using purposive sampling technique with inclusion and exclusion criteria. Data collection was performed using a Likert scale question method with 30 questions created by researchers and carried out validity and reliability tests. Data analysis is univariate to see the frequency distribution. The results showed as many as 80 respondents (53.7\%) experienced excellent service. Offering excellent service capabilities (Ability, Attitude, Appearance, Attention, and Action) for nurses who can improve service quality and patient satisfaction.
\end{abstract}




\section{Pendahuluan}

Rumah Sakit merupakan salah satu bagian sistem pelayanan kesehatan yang secara garis besar memberikan pelayanan untuk masyarakat. Menurut Undang Undang RI No. 44 Tahun 2009 Rumah Sakit adalah institusi pelayanan kesehatan yang menyelenggarakan pelayanan kesehatan perorangan secara paripurna yang menyediakan pelayanan rawat inap, rawat jalan, dan gawat darurat. Pelayanan kesehatan di rumah sakit merupakan salah satu faktor penentu citra dan mutu rumah sakit. Upaya pelayanan kesehatan dapat mencapai hasil yang optimal dengan meningkatkan Pelayanan keperawatan (Nursalam, 2014).

Pelayanan keperawatan merupakan suatu bentuk pelayanan profesional yang merupakan bagian integral dari pelayanan kesehatan didasarkan pada ilmu dan kiat keperawatan kepada individu, kelompok, atau masyarakat dalam keadaan sehat maupun sakit (Depkes RI, 2018). Pelayanan keperawatan sebagai indikator kualitas pelayanan kesehatan menjadi salah satu faktor penentu citra institusi pelayanan kesehatan di mata masyarakat, hal ini terjadi karena perawat merupakan kelompok profesi dengan jumlah terbanyak, paling depan dan terdekat dengan penderitaan, kesakitan, serta kesengsaraan yang dialami pasien dan keluarganya (Tjiptono, 2016).

Perawat sebagai salah satu pemberi pelayanan kesehatan, di tuntut harus memiliki ilmu pengetahuan, sikap dan penampilan yang baik dalam memberikan pelayanan kepada pasien, hal tersebut bertujuan untuk menciptakan seorang perawat tidak hanya sekedar memiliki pengetahuan yang hebat akan tetapi seorang perawat harus memberikan dan melaksanakan ilmu pengetahuan yang telah didapat dengan cara bersikap dan berpenampilan yang baik kepada pasien agar mereka merasakan kepuasan terhadap pelayanan yang diberikan (Kelana, 2015). Masyarakat yang puas dengan pelayanan yang didapatkan cenderung akan mematuhi rencana pengobatan yang telah disepakati, namun sebaliknya masyarakat yang kurang puas cenderung tidak mematuhi dan akan berganti ke fasilitas pelayanan kesehatan lain atau rumah sakit lain, (Desiyanti, 2017). Untuk mempertahankan kesetiaan pengguna layanan banyak pihak rumah sakit mengembangkan program pelayanan kesehatan yang berkualitas bagi para konsumen dalam memenuhi kepuasan terhadap pelayanan kesehatan yang didapat dengan cara memberikan pelayanan prima (service excellence).

Pelayanan prima (service excellence) adalah pelayanan dengan standar kualitas yang tinggi dan selalu mengikuti perkembangan kebutuhan pelanggan setiap saat, secara konsisten dan akurat (handal). Berorientasi kepada kepuasan pelanggan, selalu mengikuti perkembangan standar internasional/ISO, dan menerapkan manajemen mutu total serta kesadaran mutu yang tinggi (Rahmayanty, 2013). Pelayanan prima merupakan sikap atau cara pemberi layanan yang berperan besar dalam menciptakan kepuasan bagi klien. Menurut (Lassere, 2010) menciptakan pelayanan yang prima tidak harus mahal, misalnya sopan, senyum, dan ramah kepada klien merupakan hal yang gratis yang dapat dilakukan bagi seluruh pemberi layanan. Faktor - faktor yang harus di terapkan oleh pegawai dalam memberikan pelayanan prima (service exellence), meliputi kemampuan (ability), sikap (attitude), penampilan (appearance), perhatian (attention), tindakan (action) dan tanggung jawab (accountability). Pelayanan prima sendiri membuat suatu pelayanan menjadi berkualitas dan berdampak pada kepuasan pasien (Barata, 2016).

Pasien sebagai pengguna jasa pelayanan keperawatan menuntut pelayanan keperawatan sesuai dengan haknya, yakni pelayanan keperawatan yang bermutu dan paripurna, oleh karena itu pelayanan keperawatan memiliki kontribusi sangat besar terhadap kualitas pelayanan. Persepsi pasien menurut (Tjiptono, 2016) merupakan perlakuan yang melibatkan penafsiran melalui proses pemikiran tentang apa yang dilihat, dengar, alami atau dibaca, sehingga persepsi sering mempengaruhi tingkah laku, percakapan serta perasaan seseorang. Persepsi yang positif akan mempengaruhi rasa puas seseorang dalam bentuk sikap dan perilakunya terhadap pelayanan kesehatan, begitu juga sebaliknya persepsi negatif akan ditunjukan melalui kinerjanya. Menurut (Puspita, 2009) persepsi pasien terhadap kualitas pelayanan dipengaruhi oleh harapan terhadap pelayanan yang di inginkan. Harapan ini dibentuk oleh apa yang pasien dengar dan juga rasakan sehingga akan menimbulkan kepuasan pada diri pasien mengenai kualitas 
pelayanan yang telah dirasakan oleh pasien.

Salah satu tolak ukur kualitas pelayanan dapat dilihat dari kepuasan pasien (Munijaya, 2013). Ketidakpuasan pasien sering kali di alami dalam kehidupan sehari - hari seperti sikap dan perilaku petugas rumah sakit yang acuh, tidak ramahnya petugas kesehatan serta hal lainnya yang membuat pasien merasa tidak puas akan pelayanan yang di dapatkan. Pasien yang merasa tidak puas akan komplain pada pihak rumah sakit, bahkan beberapa pasien pindah pada rumah sakit lain.

$$
\text { Rumah Sakit Dustira telah }
$$

memberikan pelayanan prima serta paripurna sesuai visi dengan menerapkan pelayanan prima pada setiap ruangan serta mengikutsertakan perawat baru maupun telah bekerja lama pada seminar pelayanan prima (service excellence) dalam keperawatan yang di adakan sendiri oleh pihak Rumah Sakit Dustira setiap tahunnya, sehingga seluruh perawat memiliki sertifikat pelayanan prima (service excellence). Program pelayanan prima terbukti telah diterapkan pada setiap tenaga kerja di Rumah Sakit Dustira karena pada tahun 2018 Rumah Sakit Dustira telah berhasil memperoleh Sertifikat "The Best Hospital With Service Exellence Of The Year".

Berdasarkan hasil rekapitulasi laporan pelaksanaan, evaluasi, rekomendasi dan tindak lanjut survey kepuasan pasien oleh Kepala Instalasi Rawat Inap bulan januari hingga september tahun 2018 dengan materi survey perawat berdasarkan poin - poin kelengkapan dan ketepatan informasi, penurunan kecemasan, perawat terampil dan profesional, pasien merasa nyaman, terhindar dari bahaya, serta perawat ramah dan empati. Di dapati 5 ruangan dengan penilaian terendah dari total 19 ruangan yang ada di RS Tk. II 03.05.01 Dustira Cimahi, yaitu ruangan Talaga Bodas (Penyakit Dalam Pria Kelas 3) total nilai rata - rata $70,0 \%$, Patuha (Penyakit Dalam Wanita Kelas 3) total nilai rata - rata 73,5\%, Cakra Buana (Syaraf) total nilai rata - rata $78,6 \%$. Halimun (Ruang Penyakit Jiwa) total nilai rata - rata $76,8 \%$, Kencana (Perina) total nilai rata - rata $82,1 \%$.

Setelah melakukan oberservasi dan wawancara terhadap 10 pasien mengenai pelayanan perawat yang dilakukan pada saat studi pendahuluan di Ruangan Talaga
Bodas (Penyakit Dalam Pria Kelas 3) didapati hasil pengamatan peneliti sesuai dengan dimensi dari pelayanan prima (service excellence) menurut Barata (2016), diantaranya kemampuan (ability), sikap (attitude), penampilan (appearance), perhatian (attention), tindakan (action) dan tanggung jawab (accountability). Terdapat 5 dimensi pelayanan prima yang kurang maksimal diterapkan seperti pada dimensi kemampuan (ability), perawat melaksanakan tindakan keperawatan secara terburu - buru karena terkendala oleh waktu serta jumlah pasien yang banyak, tak hanya itu perawat kurang memperhatikan keamanan diri seperti lupa memakai handscone dan tidak menjalankan 5 tahapan cuci tangan.

\section{METODE PENELITIAN}

Rancangan atau desain penelitian yang digunakan adalah jenis penelitian survei analitik yaitu survei atau penelitian yang mencoba menggali bagaimana dan mengapa fenomena itu terjadi. Pendekatan ini dilakukan karena ingin melihat gambaran pelayanan prima (Ability, Attitude, Appearance, Attention, dan Action) di ruang rawat inap Talaga Bodas (Penyakit Dalam Kelas 3) RS Tk. II 03.05.01 Dustira Cimahi tahun 2019.

Populasi dalam penelitian ini adalah pasien di ruang rawat inap Talaga Bodas RS Tk. II 03.05.01 Dustira Cimahi bulan maret 2019 sebanyak 237 pasien. Teknik pengambilan sampel pada penelitian ini menggunakan teknik penelitian Purposive Sampling. Kriteria Inklusi Pasien yang menggunakan ruang rawat inap Talaga Bodas, Pasien dengan GCS Composmentis, dan Pasien yang bersedia menjadi responden. Kriteria Eklusi Pasien dengan kondisi sakit berat, Pasien yang sedang diberikan tindakan, dan Pasien yang tidak bersedia menjadi responden. Sampel di ruang rawat inap Talaga Bodas (Penyakit Dalam Pria Kelas 3) RS Tk. II 03.05.01 Dustira Cimahi 2019 kepada responden sebanyak 149 pasien tidak terdapat kriteria eklusi, semua responden memenuhi kriteria inklusi.Teknik pengumpulan data dalam penelitian ini adalah dengan menggunakan data primer. Pengumpulan data yang didapat langsung oleh peneliti yang diperoleh berdasarkan hasil pengisian kuesioner oleh reponden di ruang awat inap Talaga Bodas RS Tk. II 03.05.01 Dustira Cimahi 2019, kemudian dihimpun, ditata, dianalisis untuk menjadi informasi 
yang dapat menjelaskan suatu fenomena. Instrumen kuesioner dalam penelitian ini dibuat oleh peneliti dengan 30 pertanyaan dan dilakukan uji validitas dan uji reabilitas kepada 20 orang pasien. Hasil uji validitas dengan nilai ( $\mathrm{r}$ pearson) $\geq 0,44$ tabel dan uji reliablitiasnya adalah Alpha $(0,950)>(0,6)$ sehingga data reliabel. instrumen yang digunakan adalah kuesioner dalam bentuk pertanyaan dengan skala Likert. Instrumen yang digunakan untuk mengukur pelayanan prima perawat (ability, attitude, appearance, attention, dan action). Etik Penelitian dilakukan melalui Komisi Etik Penelitian Kesehatan STIKes Jenderal Achmad Yani dan memperoleh persetujuan etik dengan nomor: 24/KEPK/V/2019.

\section{HASIL DAN PEMBAHASAN}

Analisis univariat dilakukan untuk melihat gambaran distribusi frekuensi responden berdasarkan pelayanan prima perawat di ruang rawat inap Talaga Bodas (Penyakit Dalam kelas 3) RS Tk. II 03.05.01 Dustira Cimahi 2019.

Tabel 1 Distribusi frekuensi Pelayanan Prima Perawat di Ruang Rawat Inap Talaga Bodas (Penyakit Dalam Pria Kelas 3) RS Tk. II 03.05.01 Dustira Cimahi 2019

\begin{tabular}{ccc}
\hline Variabel & F & (\%) \\
\hline $\begin{array}{c}\text { Pelayanan Belum } \\
\text { Prima }\end{array}$ & 69 & $46,3 \%$ \\
\hline Pelayanan Prima & 80 & $53,7 \%$ \\
\hline Total & 149 & $100 \%$ \\
\hline
\end{tabular}

Berdasarkan hasil analisa pada tabel 1 diatas dapat diketahui bahwa dari 149 responden, sebagian besar responden yaitu 80 orang $(53,7 \%)$ memilih pelayanan prima. Gambaran hasil analisis pada penelitian ini menunjukan dari 149 responden yang merasakan pelayanan belum prima sebanyak 69 orang $(46,3 \%)$ dan pelayanan prima sebanyak 80 orang $(53,7 \%)$, dengan demikian dapat disimpulkan bahwa pelayanan prima dapat membantu menaikan kepuasan pasien. Keberhasilan perawat dalam mengembangkan dan melaksanakan pelayanan prima tidak terlepas dari kemampuan dalam pemilihan konsep pendekatannya.

Pelayanan prima menurut Barata (2016) membuat pelanggan merasa penting, melayani dengan ramah, tepat dan cepat, pelayanan dengan mengutamakan kepuasan pelanggan, menempatkan pelanggan sebagai mitra, pelayanan optimal yang menghasilkan kepuasan pelanggan, kepedulian kepada pelanggan untuk memberikan rasa puas, dan upaya layanan terpadu untuk kepuasan pelanggan. Terdapat tiga hal pokok di dalam definisi pelayanan prima yaitu pendekatan sikap yang berkaitan dengan kepedulian terhadap pasien, upaya melayani pasien dengan tindakan terbaik serta terdapat tujuan tim perawat untuk dapat memuaskan pasien dengan berorientasi kepada standar layanan tertentu. Beberapa hal yang harus diperhatikan perawat untuk dapat memberikan pelayanan prima (service excellence) yaitu kemampuan (ability), penampilan (appearance), sikap (attitude), perhatian (attention), tindakan (action). Berdasarkan hasil analisa penelitian sebagian besar responden merasakan pelayanan prima perawat, hal tersebut dibuktikan dengan hasil analisis data pada pelayanan prima sebanyak $(53,7 \%)$ dan pelayanan belum prima sebanyak (46,3\%). Pelayanan prima berpengaruh besar untuk meningkatkan kepuasan pasien hal tersebut ditunjang berdasarkan hasil dari kuesioner penelitian variabel pelayanan prima yang di isi oleh pasien. Pada pertanyaan variabel pelayanan prima yaitu pasien merasa puas karena perawat di ruang rawat inap Talaga Bodas (Penyakit Dalam kelas 3) memberikan pelayanan dengan cepat mendapat perolehan tinggi, artinya pasien puas karena merasa kebutuhannya terpenuhi tanpa harus menunggu waktu lama untuk mendapatkan pelayanan yang optimal hal tersebut sesuai dengan apa yang diharapkan oleh pasien.

Pertanyaan selanjutnya yaitu perawat selalu berpenampilan rapi saat melakukan pelayanan terhadap pasien sehingga pasien merasa perawat telah memberikan pelayanan prima karena tidak hanya pelayanan saja yang dinilai tapi penampilanpun turut andil dalam penilaian pelayanan prima. Pada pertanyaan selanjutnya yaitu perawat menawarkan beberapa pilihan informasi kepada pasien jika diperlukan merupakan salah satu bentuk dari pelayanan prima terhadap pasien, pasien serta keluarga merasa sangat terbantu dan terarah untuk menentukan pengobatan yang terbaik 
untuk pasien. Pada pertanyaan terakhir yang mendapatkan perolehan tinggi pada kuesioner variabel pelayanan prima yaitu perawat selalu melakukan pengkajian kepada pasien hal ini dapat dirasakan oleh pasien karena pasien merasa diperhatikan dengan pelayanan tersebut.

Keberhasilan dalam mengembangkan dan melaksanakan pelayanan prima di Rumah Sakit Dustira ditunjang melalui visi memberikan pelayanan kesehatan yang prima dan paripurna, dengan adanya visi tersebut Rumah Sakit Dustira menerapkan pelayanan prima kepada seluruh pegawai khususnya perawat yang bekerja di Rumah Sakit Dustira dengan mengikutsertakan perawat baru maupun telah bekerja lama untuk mengikuti seminar pelayanan prima (service excellence) dalam keperawatan yang diadakan sendiri oleh pihak Rumah Sakit Dustira setiap tahunnya sehingga seluruh perawat memiliki sertifikat pelayanan prima. Program pelayanan prima terbukti telah diterapkan pada setiap tenaga kerja di Rumah Sakit Dustira karena pada tahun 2018 Rumah Sakit Dustira telah memperoleh Sertifikat "The Best Hospital With Service Excellence of The Year", hal tersebut dapat membuktikan bahwa pentingnya menerapkan pelayanan prima kepada perawat agar perawat dapat mengetahui cara memberikan pelayanan optimal sehingga pasien merasa puas terhadap pelayanan yang telah diberikan. Saran penelitian diharapkan menjadi landasan untuk menerapkan pelayanan prima (Ability, Attitude, Appearance, Attention, dan Action ) kepada perawat yang dapat meningkatkan kualitas pelayanan serta kepuasan pasien dan diharapkan untuk penelitian selanjutnya dihubungkan dengan kepuasan pasien dan faktor lain dalam aspek pasien.

\section{KESIMPULAN}

Gambaran umum pelayanan prima dalam penelitian ini sebanyak 69 orang $(46,3 \%)$ merasakan pelayanan belum prima dan sebagian besar responden yaitu 80 orang $(53,7 \%)$ memilih pelayanan prima

\section{UCAPAN TERIMAKASIH}

Ucapan terima kasih kepada Rumah Sakit Tk II 03.05.01 Dustira Kota Cimahi dan STIKes Jenderal Achmad Yani Cimahi.

\section{DAFTAR PUSTAKA}

Barata, A. A. (2016). Dasar Dasar Pelayanan Prima. Jakarta, Indonesia: PT Elex Media Komputindo.

Departemen Kesehatan Republik Indonesia. (2018). Dipetik januari 23, 2019, dari Depkes RI: www.depkes.go.id

Desiyanti, M. (2017). Hubungan Dimensi Mutu Pelayanan Kesehatan Dengan Kepuasan Pasien Rawat Inap Kebidanan RSUD Dr.Soekardjo. Dalam I. Pohan, Jaminan Mutu Layanan Kesehatan. Jakarta: EGC.

Kelana, M. T. (2015). Pengaruh Penerapan Pelayanan Prima (Service Excellence) Perawat Terhadap Tingkat Kepuasan Pasien Di Rumah Sakit Universitas Tanjungpura Kota Pontianak. Dipetik februari 1, 2019, dari http://jurnal.untan.ac.id/index.php/jmkep erawatanFK/article/view/11004

Lassere. (2010). Pengaruh Pelayanan Prima Terhadap Kepuasan Pelanggan. Dipetik februari 5, 2019, dari http://eprints.unm.ac.id/10107/

Munijaya , P. (2013). Manajemen Kesehatan (4 ed.). Jakarta: EGC Kedokteran.

Nursalam. (2014). Manajemen Keperawatan: Aplikasi dalam Praktik Keperawatan Profesional. Jakarta Selatan, Indonesia: Penerbit Salemba Medika.

Puspita. (2009). Pengaruh Kualitas Pelayanan Terhadap Kepuasan Pasien Rawat Inap. Dipetik maret 2, 2019, dari https://respiratory.usu.ac.id/bitstream

Rahmayanty, N. (2013). Manajemen Pelayanan Prima. Yogyakarta, Indonesia: Graha Ilmu.

Tjiptono, F. (2016). Quality \& satisfaction. Yogyakarta: Andi.

Undang-Undang Nomor 44 tahun 2009. (2009). Rumah Sakit. Retrieved from http://kesmas.kemkes.go.id/perpu/ko nten/uu/uu-nomor-44-tahun-2009-ttgrs 